\section{Research Article} \\ (C) 2020 Francisca Isi Omorodion. \\ This is an open access article licensed under the Creative Commons \\ Attribution-NonCommercial 4.o International License \\ (https://creativecommons.org/licenses/by-nc/4.0/)
}

P U B I I S H I II G

Received: 2 January 2020 / Revised: 30 January 2020 / Accepted: 7 February 2020 / Published: 10 March 2020

\title{
African Immigrant Women's Perceptions and Experiences of Intimate Partner Violence in Canada
}

\author{
Francisca Isi Omorodion
}

\author{
Department of Sociology \& Anthropology, \\ University of Windsor, Windsor, Ontario, \\ $\mathrm{N}_{\mathrm{N}} \mathrm{A}_{5}$, Canada
}

Doi: 10.36941/mjss-2020-0015

\section{Abstract}

\begin{abstract}
This paper examines the experiences of intimate partner violence among African immigrant women living in Windsor, Ontario, Canada. In-depth interviews were conducted and audio-recorded with 20 African immigrant women who have lived in Canada for five years. Interviews were transcribed verbatim and analysed using thematic content analysis. The study showed that IPV is common in African communities and affects the mental health and quality of life of survivors. The women noted that poor integration of African men into the mainstream society due to lack of gainful employment perpetuates IPV, which becomes a tool used by African men to express their authority, power and control over their women. The women called for culturally specific and relevant treatment and prevention services that would be more inclusive and meet the needs of all abused women.
\end{abstract}

Keywords: Intimate partner violence (IPV), African, immigrant women, Windsor, Canada

\section{Introduction}

World Health Organization (2002) estimates that between $16 \%$ and $52 \%$ of women experience intimate partner violence globally. This data makes domestic violence the most common form of violence against women. For example, Nasir \& Hyder (2003) reported that about $28 \%$ of pregnant women in developed societies experience violence, while a study of 36 countries noted that between $10 \%$ and $60 \%$ of ever-married or partnered women reported being abused once by an intimate partner (Amoakohene, 2004; Heise et al., 2002). An impressive body of literature shows that many women remain in abusive relationships for a number of reasons including, lack of information and knowledge of available legal and social services, difficulty in accessing these services, and little or no social support (Michalski, 2004; Tam, 2004; Roberts, 1998; Walker, 1994). For ethnic minority women, available evidence also show that in addition, gender and social inequality are also contributory factors to remaining in abusive relationships (Michalski, 2004; Dasgupta, 2000; Dobash \& Dobash, 1992).

In many developed countries like Canada, available studies show that racializsed women are more disadvantaged because of social isolation and discrimination, and language barriers in their host countries (Lee and Au, 1998; Pratt, 1995). Violence against African immigrant women in Canada may therefore be physical, emotional, psychological, sexual, social, economic and cultural. However, little is known of African immigrant women experiences of intimate partner violence in Canada. Yet, 
census data shows that 73 per cent of the immigrants coming to Canada in the 1990s were of visible minorities and an increasing population growth of Blacks from sub-Saharan Africa chooses to settle in Windsor. Windsor has been named the second fastest growing community in Ontario after Toronto, and has Canada's fourth largest foreign-born population after Toronto, Vancouver, and Hamilton (Statistics Canada, 2001). According to Rose et al., (2003), we must begin to develop policy that is sensitive to local and regional context because geography does matter in Canada.

This paper explores the perceptions and experiences of intimate partner violence among African immigrant women resident in Windsor, Ontario, Canada. Such findings would contribute to policies and programmes that can best respond to the needs of abused racialized women in Canada. On the long run, the paper would contribute to developing services that are more likely to assist and empower these women to seek support and to leave abusive relationships.

\section{Methodology}

The research was conducted in Windsor, Ontario Canada. The growing population of Blacks in Windsor informed the study. Windsor is a border city with Detroit, Michigan USA, which also allows transnational relationships. The changing socio-economic and demographic characteristics of new immigrants in Windsor have profound effects on the host society, in terms of the cultural beliefs, which new migrants bring with them especially as such cultural beliefs and values tend to affect their life outlook and goals (Gorman, 1998). Another contributing factor to the selection of Windsor is the strong relationships between the researcher and other local community-based organizations, such as African voluntary associations/groups, and other community-based organizations servicing immigrant women (Suzuki et al., 2007).

Research probes were guided by key themes from UNFPA/WHO's interview guide on violence against women. The interview guide was designed to be open-ended and to include probes for additional issues emerging during the interviews that could emerge as important concerns among the various respondents. The instrument was in English. The interview guide and informed consent forms were pre-tested with a small sample of individuals. Based on pre-test findings, minor adjustments to question were made. Pre-test allowed the research team to gain practice using the study tool; findings from the pre-tests were not included in the overall study findings.

The research protocol and tools, including informed consent forms and in-depth interviews (IDI) were submitted to the University of Windsor, Research and Ethics Board for ethical review. The project coordinator provided significant input on the research design, sampling and implementation, as well as feedback on the analysis. The project coordinator with experience conducting research and interviews was the primary interviewer.

A total of 20 in-depth interviews were conducted with African women primarily from subSaharan Africa. These women were within the age of 18 to 60 years. The study allowed the researcher to re-tell the experiences of abused women and to increase our understanding of the challenges and plight, while contributing to new ways to eliminate violence against immigrant women. Based on the ethic approval, posters were displaced in the offices of community-based organizations in Windsor. Snowball sampling was also employed in selecting respondents, where respondents initially identified further linked the research team to other respondents who were willing to be interviewed. Few individuals refused interviews once the purpose of the research was explained. Some however, were not available during the research period or were only able to participate in a short interview due to interruptions. Prior to all interviews, we provided information about the research and rights of the respondents. In addition, respondents signed consent forms to participate and to tape-record the interviews. On average the interviews lasted an average of ninety minutes. All interviews were confidential and anonymity maintained through the use of pseudonyms.

Select socio-demographic data were collected on all respondents, including age and gender. Additional information such as marital status, number of living children, and educational level were also collected from the respondents, albeit not consistently with some respondents due to 
confidentiality concerns. Using a coding system, we eliminated socio-demographic data such as names that were linked to responses from the transcripts as a measure of confidentiality protection. All audiotapes were transcribed verbatim and coded using pseudonyms. A random sample of transcripts were reviewed and compared to the original tape by the principal investigator to verify accuracy.

Research respondents received no compensation for their participation in the study. For the interviewer, transportation costs were offered to cover travel to pick up some respondents to the designated interview site. A research associate conducted the data analysis using the transcripts, interview guide and with the help of $\mathrm{N}^{*}$ Vivo software for data coding, sorting and management. Further analysis relied on a modified grounded theory approach to explore existing themes and patterns that emerge from the data and to complement initial categories generated for coding. Key findings that merged from the data are the focus of the study findings presented in this report.

\section{Results}

Key emerging themes presented below provide a summary of Black women's narratives of violence against women in Canada. Findings are presented from multiple participants' perspectives. The presentation of research findings would include the use of direct quotations from various participants to support the theme as a way of re-narrating and giving a voice to the participants' voices and narratives. Deliberate attempt is made to present the different perspectives among the participants to show the variations and similarities about the issues explored in this current study.

\subsection{Conceptualization of Violence against Women}

When asked what violence against women, particularly that by an intimate partner, most participants reported that it was an inhumane act that perpetuate power relationships between men and women, while making women the predominant victim. One participant reported that "violence is like treating some body less human and slapping, yelling and all that stuff is part of the pain. All violence is actually not right (Iyode, 29years).

Power and gender dynamics, which include men's superiority above women, allow men to be the primary decision maker. Such decision-making right perpetuates male dominance over women. According to one participant:

I'm really against the fact of women been barred from making decisions and it kind of puts her in the background of their home. The men do not let women talk because women cannot express themselves. It also reduces their confidence because the not been allowed to express them selves in any way the have not been given a chance and I'm not in support of that at all (Ebe, 46 years).

In terms of power and gender dynamics, a younger participant said:

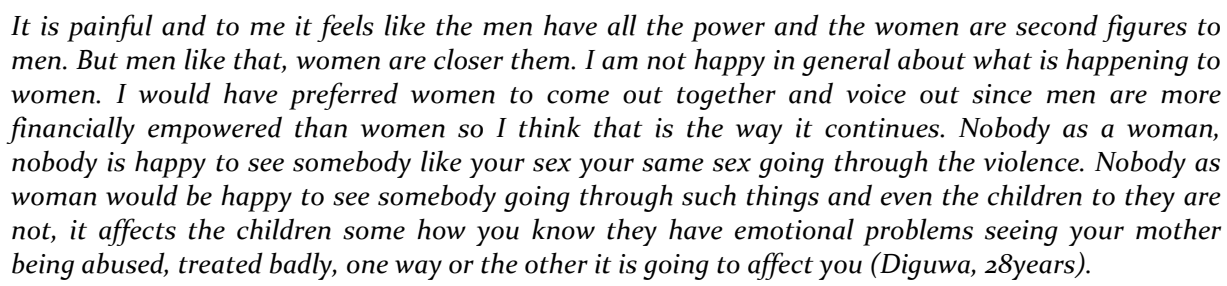

The participants gave a broad range of conceptualizations of their understandings of violence against women. Many participants reported that violence against women could be depressing. One of the participants reported that: 
It is depriving, it is depressing, and I have been depressed for years now because of this issue. It is very depriving; it removes your right from you. This means a lot, as it affects the children too. As I am deprived, the children are also deprived. If I am getting nothing the children are also going to get nothing. If I get violence and bully from him, the children receive it as well. So it means a lot in my life (Adugbo, 44years).

Some women condemned violence against women, as women like men are human and have some rights to autonomous existence. A participant said:

I see it as unfair, unwarranted because a woman like everybody else should have the freedom to make certain choices that will advance their progress and their position in life. They shouldn't say because they are women they should operate under that shadow of their partners (Anupo, 39 years).

\subsection{Risk Factors}

Although the study probed the role of race in the experiences of violence against women, the primary consensus was that violence against women has many voices and faces.

I can't say race is not an issue because whether you are Asian or Chinese it depends on the person and how they abuse the power over woman regardless of any race or any colour. If the person is an abuser, he is an abuser. I don't think there is a race in that in that matter (Iyode, 29years).

Another participant held similar view, noting that:

Not really, it depends because I know in the white community they also have a system of abuse too. It is generally a man and woman relationship and their relationship at one time or the other experiences some kind of abuse in their homes. So it is not peculiar to the black woman (Ebe, 46 years).

Contrary perspectives argued that immigration status of the women makes Black women more vulnerable to violence or abuse. This is attributed to gender disparity in entry the Canadian labour force market. The common view is that Black men experience barriers and challenges in getting a job while women are more likely to work for wages than the men. This brings changes to traditional gender ideologies that promote role segregation and the family structure based on the premise that men are the breadwinner and women the homemakers. One of the participants explained:

.... If you are talking about newly arriving in Canada, yes they are likely to be abused, If they are in Africa, a man has good job, is the boss, the go to work, they shower and eat, read a magazine. They come to Canada and come and read a news paper, some times their wives get jobs before they do for that to happen to an African man it takes some respect from him. They women comes home, she's got a job he becomes worth less, he can do anything by doing that they get angry, they get confused, they do things they don't want to do them because they have reached as situation were their ability to cope with the situation is no longer within their human being support or their brain. They fight they beat each other and sometimes they divorce (Zenora, 55years).

Another woman said:

I am not sure, but I think all women are. Maybe more immigrant women as they are very insecure when they get here and very dependent on their husbands (Flippe, 35 years).

One participant reported:

... Black women more likely not to report that whites. Immigrant women are particularly not to report. The immigrant women are less likely to report this abuse than other groups of women (Anupo, 39 years). 
Further credence was give to this perspective, when another participant noted:

Not really, it depends because I know in the white community they also have a system of abuse too. It is generally a man and woman relationship and their relationship at one time or the other experiences some kind of abuse in their homes. So it is not peculiar to the black woman (Ebe, 46 years).

Another factor that increases the vulnerability of Black women to violence and abuse was attributed to what I term here the "culture of silence" that prevents most of these women from reporting or to discuss their violence experiences. One participant said:

... Black women more likely not to report that whites. Immigrant women are particularly not to report. The immigrant women are less likely to report this abuse than other groups of women (Anupo, 39 years).

I think all women are vulnerable to violence or abuse. But more immigrant women are more vulnerable as they are very insecure when they get here and very dependent on their husbands (|Flippe, 35 years).

The general consensus is that with both partners participating in gainful employment, violence is less likely to occur in intimate partner violence.

... All women are. Maybe more immigrant women as they are very insecure when they get here and very dependent on their husbands (Flippe, 35 years).

\subsection{Factors Associated with Violence against Women}

Integration into the Canadian culture was a primary factor to everyday experiences of violence. Also, men tend to allow their public status to influence their private life, a privilege that women solely charged with the responsibilities at home and deprived from fully participating in decision-making affecting the families. A participant explained that:

I think they want to exercise power and they feel helpless outside in the real world and to be able to remain at that post they want, they bring home to their wife and their children. That is what I have gathered from my husband. He seems to be locked up in a world that he wants to be on top, but he is not like that outside the house. He comes in to the house he wants to be that. He wants a total control in the house be it in the food he wants to eat anything he wants total control all over. I think that is the main problem. It is like some one that has been deprived and has never had that free will before and now wants to dominate and control of everything, which is not possible outside the house. He does it in the house because he has such power (Adugbo, 44 years).

Another reason commonly cited was finance/money. The general belief was that financial deprivation also allows some men to use control and their masculine ideology as substitute to their limited resources.

Uh I think it is financial reasoning's. Like I said there is some people some individuals that want more power than others wherever that is coming from I have no idea well I think possibly that a lot of it comes from financial, economical (Penive, 31 years).

However, the participants argued that men had no better idea as to the other ways of controlling their aggressive behaviour. They simply want to be in control and in charge. One participant echoed the general view by noting:

I also think that it has to do with the fact that most men don't know the appropriate means to express their anger and when they feel stressed the closest thing to them is what they release on. If the woman is not there may be the pet or whatever, the animal will get it. So yes it definitely has to do with control and poor anger management (Anupo, 39 years). 


\subsection{Perceptions of the Aftermath of Violence}

Although the participants' experiences of violence spanned a long period of time between two to over ten years, the general trend is that many have not healed. These women are still hurting. One participant reported: 'I feel bad. I feel hurt that I cannot express it (Adugbo, 44years)'. Another younger women also experiencing hurt from her experiences of violence expressed being confused. She noted:

I felt hurt, I felt confused, and I didn't know what to think. I was one of the fortunate ones that didn't grow up with my dad hitting my mum and abusive languages in the house, so for me it was not the norm. It might be the norm in the community and around but in my house and in my family it wasn't so I was scared and the first thing I did was to leave the house (Diguwa, 28 years).

Another participant who expressed similar confusion reiterated:

Hum shocked, for a brief moment I thought I deserved it which was a bit sort of weird for me just because I didn't believe in violence against anybody no matter what you do but I did feel that it was sort of my fault but I got rid of that quite quickly (Penive, 31 years).

For other participants, there was some form of self-laming, particularly for not being able to retaliate. A participant reported:

Why I felt stupid? Well because I shouldn't have left him to have that much power over me to make that scared not have been able to talk to him or go to the authority (Bentu, 24 years).

\subsection{Prevention and Treatment for Violence}

While almost all participants recognized that abuse has serious social, economic and health consequences, many participants were unwilling and less likely to seek for help or treatment. Nonetheless, many participants reported that knowledge and accessibility to sourcing available services were overshadowed with fear and stigma by other community members from their blaming the victim as responsible to her abuse.

It's embarrassing to say that your husband just beat you and how do you approach such a subject and who do you tell, who are you to trust enough to tell your story or experiences. Are they going to laugh at you? Are they going to support you? If its women within your community, are they going to say go back to your husband its okay? So, who you do talk to? (Diguwa, 28 years)

I didn't talk to any one because there is no organization, nobody to listen to me and I didn't know who to turn to or where to go (Age withheld).

\subsection{Perceptions of Support Services Used}

The study also investigated the participants' experiences with the support services for abused women. Amazingly, some of the participants stressed that they have not healed as they remained in abusive intimate relationship for a long period of time. Furthermore, the presence of another woman in their relationships makes healing more difficult, particularly, as children and the women suffered deprivation. One participant's narrative, shown below, echoed the views of some women.

First of all I'm not healed. I am actually more in pain than ever knowing he is marrying another woman when he is keeping four of my children in one room. We leave in just two rooms. I know has a lot of money and a lot ground, paying this money to this woman and abandoning us. It hurts more. If we are legally separated so he and my self will know what our obligations are according to the law, he can go ahead and marry that woman and I can take good care of my self as well as my children.

Although healing and hurting prevail from experiences of violence, some women continue to 
express some affection for their abusive partner. More so, some women showed they were more willing to remain in such relationship if they could talk it over, apportion blame and apologise to one another. For example one participant noted:

The other best, which could have been the best of all, is if he could just change now. If a miracle could just happen and he could just change and apologize to me. If he could just sit down and let me tell him about how feel about all that has been done to me, he will tell me all I have done to him. We sort things out and apologize to each other and we try to sort the issues that would have been the end of it all. But I wouldn't mind. I will take in that baby and take care of the baby like my own and become a man instead of being a tyrant (Adugbo, 44 years).

Lack of information on available support services, and inability to access them, made most women to resort to other healing techniques. The trend was to rely on time, prayers and faith. One participant reported:

What has helped is time, which allowed me to sort it out. Since I haven't been seeing him, the long period of non-interaction has helped. We are so much apart so it is and I sort it out. I stop to pray and what not. When I talk about it I laugh but then it hurts me but right now I don't even care and I have to go on with my life and the country I arrived here now who cares (laughs) (Diguwa, 28 years).

Another participant reiterated that: “Talking about it again ....... believe it doesn't bother me again as it used to (Bentu, 24 years)". There were cases that have participants putting forward a false reaction and revealing their actual experiences. A woman said:

Well I am the type of person who I don't put anything in my heart I am always like laughing even when I am not happy. Laughing, singing, I feel good, I forget my problems (53 years).

While some women reported a desire to be able to access existing support and treatment services without specific service, to be staffed by cultural competent workers. Some also suggested the need for specialized services for the Black communities. Equally important, many participants raised the need to make support services available to both the women and their intimate partner violation. Another perspective is the need to broaden our policy and services, in order to make them available and susceptible. A woman suggested that out reach activities are more likely to raise women's awareness about the available support services and the importance for seeking and utilizing such services in order to heal and to minimize the serious social and health consequences of violence. A participant said:

The focus is to be on improved treatment facilities and process, especially those provided for victims of violence. What should be improved is increase awareness through outreach activities that are likely to broaden the horizon of their services. They should get into the community and teach them about issues of violence against women so as to increase their awareness about the consequences.

\subsection{Reasons why women remain in Violent Relationships}

Although violence is a common experience among African women, many remained in the relationships. We probed why women remain in violent and abusive relationships. The specific reasons provided are located in the fact that most of these women came to Canada either as dependants of their husband or as refugees. More importantly, domestic violence, particularly violence against women in most African societies and cultures, was acceptable, condoned and never questioned. Women were seen as properties of men, as daughters to their father, as wives to their husbands and as a widow to her son and in-laws. The fact that most of the study participants may have accepted abuse as part of their relationships, it became more difficult if not impossible to question or resist similar behaviours in Canada. In addition, changes in social and economic status of 
men, who were once primary breadwinners in their country of origin, only to settle in Canada and not find a job, and if they do find one, it is often of lower status to their position back in their countries. This situation is further worsened by the fact that most of African women become the primary income-earner, because she tended to get jobs much earlier than their men. One of the participants said:

I think they want to exercise power and they feel helpless outside in the real world and to be able to remain at that post they want, they bring home to their wife and their children. That is what I have gathered from my husband that is the sickness he has. He seems to be locked up in a world that he wants to be on top, but he is not like that outside the house. He comes in to the house he wants to be that. He want s total control in the house be it in the food he wants to eat anything he wants total control all over. I think that is the main problem. Its like some one that has been deprived and has never had that free will before and now wants to dominate and control of everything which is not possible outside the house. He does it in the house because he has such power (44 yrs).

More specific reasons were attributed to the fact that marriages are between families and not individuals. Things that happen in intimate partner relationships were seen as private and not for public consumption. The punishment given to the abuser leads to conflict and dissent between two partners and their families. One participant's story corroborated this position, when she noted:

It's embarrassing to say that your husband just beat you and how do you approach such a subject and whom do you tell, whom do you trust to tell. Are they going to laugh at you? Are they going to support you? If its women within your community, are they going to say go back to your husband its okay? So you do you talk to? So yes they where barriers ( 28 yrs).

\section{Discussions and Conclusion}

This current shows that African women conceptualize violence against women as "inhumane" and "depressing." This finding is similar to other studies that have noted that psychological distress is a consequence of women's experiences of abuse (Beitch-man et al., 1992; Coker et al., 2003). Yet, many victims of intimate partner violence choose to remain in abusive relationships particularly because of the control and power their partners have over them. Hence, this current study supports existing literature that male dominance and power place women in subordinate position as a passive wife and nurturing mother. And, these conditions cause some women to feel helpless and powerless to leave abusive relationships. According to Michalski (2004:658), "wife assault represents a systematic form of domination and social control by men." Hence, it has been estimated that of the $95 \%$ of heterosexual relationships, where domestic violence occurs, men are often the perpetuators and women are the victims (Bernhard, 2000:68). Hence feminists hold that men dominate and control women in intimate relationships through the use of violence and abuse. At the same time, women are expected to obey their husbands and partners, an expectation often reinforced with the use of violent behaviour.

One significant finding is that despite the fact that these women are now resident in Canada, a country where laws on violence against women are enforced women are less willing to have their partners prosecuted because of shame and the likelihood that they would face social isolation from their African community. Furthermore, calling the police and may negatively impact on the relationships between the families of both partners in their country of origin. This finding supports other arguments that culture is a significant factor in the perceptions of spousal abuse (Gabler et al., 1998; Yick \& Agbayani-Sietwert, 1997). More importantly, most of the respondents come from home countries that condone violence against women and are often not reported because of lack of protection and prosecution from abuse (Omorodion, 1993; Menjivar, 1999). This cultural expectation was reflected in our findings, when many women reported that in their culture, violence in the family is seen as private and not meant for public consumption. As such, reporting incidence of violence 
might result in experiences of social isolation rather than social support. Nevertheless, the respondents called for the need of more secured and empowered to talk about violence against women in Canada, a finding, which supports the studies from other, racialized groups in Canada (e.g. Gill, 2004).

Despite the differences in the respondents' ethnicity, language, religion, custom, and values, experiences of violence occurred at all social, economic and ethnic levels, which have also been demonstrated in other studies on intimate partner violence (Ferraro, 1989; Hass et al., 2000; Kofman et al., 2000; Menjivar \& Salcido, 2002). Similarly, the findings of this current study that the respondents' fear of loosing their spouse, and their status also supports other studies (e.g. Hass et al., 2002; Lee \& Mechanic, 2002; Ely, 2004; Gill, 2004; Michalski, 2004). Some of these past literature hold that the worsened conditions that immigrant women face in their host countries, such as language barriers, uncertain legal statuses, prevent victims of violence from leaving such relationships (Lee \& Mechanic, 2002; Ely, 2004; Gill, 2004; Michalski, 2004). In addition, other studies also noted that conditions such as language barriers, uncertain legal statuses serve to prevent women from reporting abuse and for early interventions, which invariably reinforce men's control and power over women (Bui \& Morash, 1999; Jang et al., 1991).

Moreover, the current study found that most of the respondents experienced intimate partner violence irrespective of their employment status. This finding bears credence to other studies that women remain victims of violence although their labour force participation may increase their power to bargain, re-negotiate their conditions, and give them some level of control over their income or resources (Bui \& Morash, 1999; Menjivar, 1999; Menjivar \& Salcido, 2002). Rather, while African women gain economic power due to early entry into the labour force, African men hold on to their patriarchal processes such as male superiority power and control over the women to perpetuate their traditional position of authority in their families (Menjivar, 1999).

In conclusion, this current study identified some interesting emerging themes that need to be considered in the efforts to eliminate violence against women, particularly that experienced by African women from their by intimate partners in Canada. This research indicates that we need more outreach activities and a holistic approach, which includes the integration of men, women, children, and communities at large, in order to address lack of awareness of the social and legal implications of abuse, reach consensus on more culturally-appropriate and effective interventions to eliminate violence against women, as well as address policy and programmatic gaps as ways to empower and to promote the rights and well being of African women resident in Canada. Of utmost importance is to raise Africa women's awareness of their rights and the possibility to exercise their rights. Furthermore, this current study lends a voice to other calls for cultural competence and advocacy policy and programs to eliminate violence against immigrant women (Ely, 2004' Tam, 2004)

\section{References}

Amoakohene, M. I. (2004). Violence against women in Ghana: A look at women's perception and review of policy and social responses. Social Science and Medicine, 59, 2373-2385.

Beitchman, J. H., Zucker, K. J., Hood, J. E., daCosta, G. A., Akman, D., \& Cassava, E. (1992). A review of the longterm effects of child sexual abuse. Child Abuse and Neglect, 16(1), 101-118.

Bernhard, L. A. (200o). Physical and sexual violence experienced by lesbian and heterosexual women. Violence against Women, 6(1), 68-79.

Bui, H. N. \& Morash, M. (1999). Domestic violence in the Vietnamese immigrant community: An exploratory study. Violence against Women, 5(7), 769-795.

Coker, A. L., Watkins, K. W., Smith, P. H., \& Brandt, H. M. (2003). Social support reduces the impact of partner violence on health: application of structural equation models. Preventive Medicine, 37(3), $259^{-} 267$.

Dasgupta, S. (200o). Charting the course: An overview of domestic violence in the South Asian community in the United States. Journal of Social Distress and the Homeless, 9, 173-185.

Dobash, R. E. \& Dobash, R. P. (1992). Women, violence and social change. London: Routledge. 
Ely, G. E. (2004). Domestic violence and immigrant communities in the United States: A review of women's unique Needs and recommendations for social work practice and research. Stress, Trauma, and Crisis, $7(4)$, $1543-4613$.

Ferraro, K. (1989). Policing battered women. Social Problems, 36(1), 61-74.

Gabler, M., Stern, S. E., \& Miserandino, M. (1998). Latin American, Asian, and American cultural differences in perceptions of spousal abuse. Psychological Reports, 83, 587-592.

Gill, A. (2004). Voicing the silent fear: South Asian women's experiences of domestic violence. The Howard Journal of Criminal Justice, 43(5), 465-483.

Hass, G. A., Dutton, M., \& Orloff, L. E. (200o). Lifetime prevalence of violence against Latina immigrants: Legal and policy implications. International Review of Victimology, 7, 93-113.

Jang, D., Lee, D., \& Morello-French, R. (1991). Domestic violence in the immigrant and refugee community: Responding to the needs of immigrant women. Response to the Victimization of Women and Children, 13, $2-7$.

Kofman, E., Phizacklea, A., Raghuram, P. \& Sales, R. (200o). Gender and international migration in Europe: Employment, welfare and politics. London: Routledge.

Lee, M. Y. \& AU, P. (1998). Chinese battered women in North America: Their experience and treatment. In Roberts, A. R. (ed.), Battered women and their families: Intervention, strategies and treatment program, New York: The Springer Publishing, pp. 448-482.

Lee, R. K., Thompson, V. L., \& Mechanic, M. B. (2002). Intimate partner violence and women of color: A call for innovations. American Journal of Public Health, April, 92(4), 530-534.

Menjivar, C. (1999). The intersection of work and gender: Central American immigrant women and employment in California. American Behavioural Scientist, 42(4), 595-621.

Menjivar, C. (2000). Fragmented ties: Salvadoran immigrant networks in America. Berkeley: University of California Press.

Menjivar, C. \& Salcido, O. (2002). Immigrant women and domestic violence: Common experiences in different countries. Gender and Society, 16(6), (Dec.), 898-920.

Michalski, J. H. (2004). Making sociological sense out of trends in intimate partner violence: The social structure of violence against women. Violence against Women, 10(6), 652-675.

Muhammad, M., \& Haj-Yahia, M. M. (2002). Attitudes of Arab women toward different patterns of coping with wife abuse. Journal of Interpersonal Violence, 17(7), 721-745

Nasir, K., \& Hyder, A. A. (2003). Violence against pregnant women in developing countries: Review of evidence. European Journal of Public Health, 13(2), 105-107.

Omorodion, F.I. (1992). The social context of wife battering in Benin City. In Mere N. Kisekka (ed.) Women's health issues in Nigeria, Zaria: Tamaza Publishing Company Limited, pp. 169-182.

Pratt, A. (1995). New immigrant and refugee battered women: The intersection of immigration and criminal justice policy. In Valverde, M., MacLeod, L., \& Johnson, K. (eds.). Wife assault and the Canadian criminal justice system, Toronto: University of Toronto, Centre of Criminology, pp. 84-103.

Raj, A., Liu, R., McCleary-Sills, and Silverman, J. G. (2005). South Asian victims of intimate partner violence more likely to than non-victims to report sexual health concerns. Journal of Immigrant Health, 7, 2, April, 85-91.

Roberts, A. R. (2004), Battered women and their families: Intervention, strategies and treatment program, New York: The Springer Publishing

Rose, D., Preston, V., Dyck, I. (2003). Women, gender and immigration: perspectives and challenges, Horizons, 5(2), - feature Columnist.

Statistics Canada (2001). Census of Canada: Population Characteristics. Ottawa: Ministry of Industry, Science and Technology.

Suzuki, L. A., Ahluwalia, M. K., Arora, A. K. and Mattis, J. S. (2007). The pond you fish in determines the fish you catch: Exploring strategies for qualitative data collection. The Counseling Psychologist, 35(2), 295 - 327.

Tam, D. (2004). Culturally responsive advocacy intervention with abused Chinese-Canadian women. British Journal of Social Work, 34, 269-277.

Walker, L. E. A. (1994). Abused women and survivor of therapy: A practical guide for the psychotherapist. Washington, DC: American Psychological Association.

World Health Organization (2002). World report on violence and health. Geneva: World Health Organization.

Yick, A. G., \& Agbayani-Stewert, (1997). Perceptions of domestic violence in the Chinese community. Journal of Interpersonal Violence, 12, 834-846. 